\title{
Characterization of Fusarium solani Populations Associated with Spanish Strawberry Crops
}

\author{
M. Villarino, ${ }^{1}$ E. De la Lastra, ${ }^{2}$ M. J. Basallote-Ureba, ${ }^{2}$ N. Capote, ${ }^{2}$ I. Larena, ${ }^{1}$ P. Melgarejo, ${ }^{1}$ and A. De Cal ${ }^{1, \dagger}$ \\ ${ }^{1}$ Department of Plant Protection, INIA, Carretera de La Coruña Km 7,5. 28040 Madrid, Spain \\ ${ }^{2}$ IFAPA Centro Las Torres, Apdo. Oficial, 41200 Alcalá del Rio, Sevilla, Spain
}

\begin{abstract}
Fusarium solani is an emerging pathogen reported on Spanish strawberry crops both in nurseries and in fruit production fields, causing wilt and root rot. Pathogenicity, morphocultural characteristics, and sensitivity to biocides of $103 \mathrm{~F}$. solani isolates recovered from symptomatic strawberry plants and soils from both Spanish strawberry areas were determined. The differences of isolates within and between nurseries and field crops in relation to these parameters were analyzed. Considerable variability in morphological and pathogenic characteristics was observed among the isolates in both areas. The majority of isolates

$70 \%$ of pathogenic isolates caused stunting on plants. The morphological characters that best explain the $F$. solani variability $(86.85 \%)$ were colony color and the presence of macroconidia on culture medium. The sensitivity to the fumigants tested was similar between the isolates from nurseries and fruit production fields, showing greater sensitivity to the field doses of dazomet and chloropicrin. However, the isolates were less sensitive to metam sodium and poorly sensitive to $1,3-$ dichloropropene. This work can contribute to the advancement of sustainable production of strawberry.
\end{abstract} were not pathogenic $(62 \%)$, and only $38 \mathrm{~F}$. solani isolates $(37.62 \%)$ caused disease on strawberry plants under controlled conditions; $52.63 \%$ of pathogenic isolates induced low severity symptoms. Almost

Keywords: pathogenesis, color colony, macroconidia, secondary pathogen, emergence disease

Both fruit and runner plants of strawberry (Fragaria $\times$ ananassa Duchesne) are important crops in Spain. In 2016, there were 6,867 ha of fruit production, yielding 377,596 metric tons (t) of strawberry fruit. Huelva (southwestern Spain) is the main producer under plastic macro-tunnels. In 2016, this province contributed $97 \%$ of the production, of which more than $80 \%$ was exported with a wholesale price of 1,037 euros/t from December to May-June. Overall, the 2016 strawberry fruit production was valued at 392 million euros in Spain (Anuario Estadística Agraria 2017). Each year, strawberry runners (transplants) are produced throughout October in high-elevation nurseries in Castilla-León (north central Spain) under continental climatic conditions, to be subsequently transplanted in fruit production areas in Spain and other countries, mainly belonging to the European Union (EU). In 2015, more than 650 million strawberry runners were produced on an area of approximately $1,500 \mathrm{ha}$, which is one of the main runner production areas in the EU (Anuario Estadística Agraria 2016). Preplant soil fumigation is a critical point in the production process of the Spanish strawberry crops to control soil-borne plant pathogens (De Cal et al. 2004).

Diseases caused by soil-borne plant pathogens such as Phytophthora cactorum, Verticillium dahliae, Rhizoctonia spp., Pythium spp., and Fusarium spp. are the most important diseases in Spanish strawberry nurseries without soil disinfestation, particularly in fields where there were previously horticultural crops (De Cal et al. 2004). P. cactorum (de los Santos et al. 2002), Colletotrichum acutatum (Garrido et al. 2008), Macrophomina phaseolina (Avilés et al.

\section{${ }^{\dagger}$ Corresponding author: A. De Cal; cal@inia.es}

Funding: This study was financed by Plan Nacional de I + D, Ministry of Economy and Competitiveness, Spain, project RTA2013-00062-C05-E, with co-financing from the 2014-2020 ERDF support: "Smart Growth" Operational Programme.

The author(s) declare no conflict of interest.

Accepted for publication 12 March 2019.

() 2019 The American Phytopathological Society
2008), Pestalopsis clavispora (Chamorro et al. 2016), Fusarium oxysporum (Arroyo et al. 2009), and Fusarium solani (Pastrana et al. 2014) are the most important pathogens on strawberry fruit crops in the south of Spain. F. solani was associated recently with symptomatic strawberry plants both in fruit production fields (Pastrana et al. 2014) and in nurseries (Redondo et al. 2012). F. solani has also been described as a strawberry pathogen in Italy and Mexico along with other pathogens (Ceja-Torres et al. 2008; Manici et al. 2005). However, the recent emergence of $F$. solani in both Spanish strawberry production areas has unknown origin.

The F. solani species complex (FSSC) is an important pathogenic ascomycetes group (Leslie and Summerell 2006) from soil and rhizosphere that causes vascular wilt or root rot in more than 100 plant species (Michielse and Rep 2009). The main symptoms of this disease on strawberry are plant-stunting, wilting and chlorosis of leaves, and root rot. The pathogenic $F$. solani isolates are morphologically indistinguishable from nonpathogenic strains (Lievens et al. 2008). Some molecular markers have been developed to identify F. solani (Chehri 2016; Costa et al. 2017; Laurence et al. 2016; Mehl and Epstein 2007; O’Donnell et al. 1998). Among them, EF1- $\alpha$ (translation elongation factor 1-alpha), RPB2 (RNA polymerase II second largest subunit), and the ITS rDNA region + the nuclear large-subunit (LSU) rDNA gene sequences, have demonstrated to be a potent phylogenetic marker within $F$. solani (Ke et al. 2016; O'Donnell et al. 2012). Real-time PCR has also been described as a significant detection and identification tool of different F. solani (De la Lastra et al. 2018; Gao et al. 2004; Li et al. 2014; Muraosa et al. 2014).

Higher genetic diversity was identified within members of $F$. solani based on EF1- $\alpha$ sequence analysis from Spanish strawberry fruit production fields than strawberry nurseries (E. De la Lastra, personal communication). However, there are no reports concerning the morphological and pathogenic variability present in $F$. solani populations in both Spanish strawberry nurseries and fruit production fields. Consequently, further work is needed to distinguish the phenotype of isolates in these Spanish areas in association with strawberry to develop effective control strategies. Here, we characterized $F$. solani isolates recovered from strawberry plants and soil in both Spanish areas (highelevation nurseries and fruit production fields) based on morphological and pathogenic characteristics and sensitivity to soil fumigants, with 
the aim of knowing the origin and structure of the populations from both Spanish strawberry production areas.

\section{Materials and Methods}

Fungal isolates. A total of 103 isolates of $F$. solani were selected for the present study. Strains were obtained from soil (57 isolates) and symptomatic strawberry plants (46 isolates) along prospections made in 2010/11, 2011/12, 2012/13, 2014/15, 2015/16, and 2016/ 17 strawberry seasons. The isolates were conserved as single spores at the INIA (Madrid, Spain) and IFAPA Las Torres (Sevilla, Spain) collections (Table 1).

Five nurseries were sampled in 2011, 2015, and 2016 located in Navalmanzano and Arévalo localities, in Segovia and Ávila provinces, respectively. Twelve fruit production fields were sampled in Huelva and one more in Cádiz during 2010 to 2016 (Table 1).

$F$. solani isolates were also obtained from soil before fumigation and symptomatic strawberry plants along seasons in nurseries and fruit production fields. The number of prospected plants was about 800 plants per nursery and about 2,150 plants per fruit production field in each season. Symptomatic plants were incubated for $2-5$ days at $22-25^{\circ} \mathrm{C}$ before Fusarium isolation.

Twenty soil samples ( 0 to $20 \mathrm{~cm}$ in depth) in each of the four cardinal directions per nursery and year were randomly taken and pooled in a composite sample for further analysis. Soil samples in fruit production fields consisted of soil immediately below the collected plants ( 0 to $20 \mathrm{~cm}$ depth). Aliquots ( $10 \mathrm{~g}$ ) of each soil mixture were suspended in $90 \mathrm{ml}$ of sterile distilled water in 250-ml flasks and shaken for $30 \mathrm{~min}$ at $150 \mathrm{rpm}$; 10 - to 100 -fold dilutions were made, and $100-\mu l$ aliquots from undiluted and diluted suspensions were spread onto petri dishes containing potato dextrose agar (PDA) (Difco Laboratories, Detroit, MI, U.S.A.) amended with streptomycin at $0.5 \mathrm{~g} \mathrm{liter}^{-1}$ or Fusarium selective medium (Nash and Snyder 1962). Three replicate dishes were used for each soil sample, dilution, and media. Petri dishes were maintained at $20-25^{\circ} \mathrm{C}$ for 5-7 days and then Fusarium fungal colonies were isolated.

Fifty isolates were from high-elevation nurseries in north central Spain (Segovia and Ávila provinces), and 53 isolates were from southwestern Spain (Huelva and Cádiz provinces).

The isolates were grown on Czapek Agar (CA, Difco) in the dark at $22-25^{\circ} \mathrm{C}$ for mycelium and spore production for 7 days (De Cal et al. 1995), and each isolate was stored in sterile sand at $4^{\circ} \mathrm{C}$ (Delcán et al. 2002) until required. For production of microconidia to be used in pathogenicity tests, isolates were grown on Czapek Broth $(\mathrm{CB}$, Difco) with agitation (150 rpm) for 5 days.

DNA isolation of each $F$. solani isolate was performed using the DNeasy Plant Mini Kit (Qiagen GmbH, Hilden, Germany), in accordance with the manufacturer's instructions. The isolates were identified as $F$. solani by a specific PCR-based assay (Arif et al. 2012) and confirmed by sequencing of a portion of the translation elongation factor-1 alpha (EF-1 $\alpha)$ gene using primers EF1 and EF2 (Table 1) (O'Donnell et al. 1998).

Pathogenicity test. One hundred and one $F$. solani isolates (Table 1) were tested for pathogenicity on strawberry plants under growth chamber conditions. Pathogenic characterization of $F$. solani isolates was carried out by comparing their ability to cause disease on strawberry plants ('Fortuna' and 'Camarosa', both of them extensively grown in Spain) that were artificially inoculated by immersing the roots and crowns for $30 \mathrm{~min}$ in a suspension of microconidia $\left(10^{6}\right.$ conidia $\mathrm{ml}^{-1}$ ) of each isolate (groups of 10 plants per isolate were inoculated). The controls consisted of the same number of plants with their roots and crowns immersed in sterile distilled water (SDW). After inoculation, the plants were transplanted into pots with sterilized mixture of peat:perlite $(9: 1, \mathrm{vol} / \mathrm{vol})$. Plants were incubated in a controlled environment chamber adjusted to $25 / 18^{\circ} \mathrm{C}$ (day/night), $70 \%$ $\mathrm{RH}$, and a photoperiod of $16 \mathrm{~h}$ for 6-8 weeks. At the end of the experiment, pathogenic characterization was recorded by fresh plant weight reduction and disease severity rate. Disease severity was rated as follows: no symptoms (0\%), plant with yellow lower leaves (25\%), plant with necrotic lower leaves and yellow top leaves (50\%), wilted plant with lower dead leaves and top wilted leaves (75\%), and dead plant $(100 \%)$. The crowns of plants were cut longitudinally and placed in humidity chambers. After 7 days of incubation at $22 \pm$ $3^{\circ} \mathrm{C}$, the presence or absence of Fusarium was confirmed by observing Fusarium structures from diseased crown segments under a light microscope (Zeiss Axioplan; Carl Zeiss). Pathogenicity test was conducted twice.

Cultural and morphological characterization. Monosporic cultures of 103 isolates were morphologically characterized on PDA. Plugs ( $\sim 5 \mathrm{~mm})$ of 7-day-old actively growing mycelia from each isolate were placed in the center of a sterile PDA petri dish $(\sim 9 \mathrm{~cm})$ and incubated at $22 \pm 2{ }^{\circ} \mathrm{C}$ in the dark for 7 days. The colony diameter of the isolates $(\mathrm{cm})$ was measured from two perpendicular sides of the colony growth at $3,4,5,6$, and 7 days after inoculation in each plate. The growth rate $\left(\mathrm{cm} \mathrm{day}^{-1}\right)$ was calculated from daily measurements of the colony's diameter using regression analysis. The presence or absence of microconidia, macroconidia, and chlamydospores of each isolate on PDA and agar- $\mathrm{KCl}(0.6 \%)$ was observed under the optical microscope (Leslie and Summerell 2006). Colony color from top view and reverse on PDA were recorded as HTML colors (https:// html-color-codes.info). Five replicates per isolate were used and the complete assay was repeated twice.

Fumigant sensitivity tests. The sensitivity of each $F$. solani isolate (Table 1) to four fumigants was tested as described in Raposo et al. (1995). The automated quantitative method consists of the growth of each isolate in microplate wells (Nunc-Immuno plate, Thermo Scientific), which is spectrophotometrically monitored in a range of $0.60-1.98$. Four active substances usually applied to soil in nurseries and fruit production fields were tested: Dazomet (tetrahydro3, 5-dimethyl-2H-1, 3, 5-thiadiazine-2-thione, Sigma-Aldrich), metam sodium (sodium N-methyldithiocarbamate, Supleco), chloropicrin (trichloronitromethane, Symta), and 1,3-dichloropropene (Symta). Each fumigant was evaluated at nine different doses according to literature recommendation $(0.25,0.5,2.5,5.0,50,75,100,125$, and $150 \mathrm{mg}$ a.i. liter $\left.^{-1}\right)$. One hundred $\mu \mathrm{l}$ of each fumigant solution was mixed with $100 \mu \mathrm{l}$ of spore suspension $\left(10^{4}\right.$ microconidia $\left.\mathrm{ml}^{-1}\right)$ in potato dextrose broth (PDB; Difco Laboratories) in each of the microwells (100). Three replicates per isolate, fumigant, and dose were made. Absorbance was measured at $492 \mathrm{~nm}$ with a microplate reader (Multiskan Plus PV. 2.01). The first measurement was made just after filling the plate $\left(\mathrm{A}_{0}\right)$, before incubation in the dark at $22^{\circ} \mathrm{C}$ for $46 \mathrm{~h}$, with one daily monitoring of absorbance as described Guijarro et al. (2017). The concentration of fumigant at which $50 \%$ of the colony growth was inhibited was determined at least twice.

Data analysis. All data were analyzed by an analysis of variance (ANOVA) (Snedecor and Cochran 1980) using STATGRAPHICS program (XVII Centurion. Ver. 17.2.00). When the $F$ test was significant at $P=0.05$, means from each isolate were compared by StudentNewman-Keuls multiple range test (Snedecor and Cochran 1980).

Significant means for each pathogenic, morphological, and fumigant sensitivity characteristic were used to design range values for each one. These significant ranges were: confirmed Fusarium disease severity (\%) $(0 \% ; 0$ to $15 \% ; 15$ to $20 \% ; 20$ to $25 \% ; 25$ to $35 \%$; 35 to $50 \%$; $>50 \%$ ); presence (1) or absence (0) of stunting (plant weight $[\mathrm{g}])$; colony growth rate $\left.(\mathrm{cm} \mathrm{day})^{-1}\right)$ on PDA $(<0.65$; $0.7-0.75 ; 0.75-0.85 ; 0.85-0.95 ; 0.95-1 ; 1-1.09$; >1.09); presence (1) or absence ( 0$)$ of macroconidia, microconidia, and chlamydospores; colony color from top view on PDA [white (\#FFFFFF), cream (\#FFFFF0), pink (\#FFE4E1), and yellow (\#FFFACD)], reverse colony color on PDA [white (\#FFFFFF), cream (\#FFFFF0), pink (\#FFE4E1), and yellow (\#FFFACD), orange (\#FE9A2E), and dark orange (\#DF7401)]; concentration of the fumigant at which $50 \%$ of the growth is inhibited $\left(\mathrm{mg} \mathrm{liter}^{-1}\right)(0-0.25$; $0.25-0.5 ; \quad 0.5-2.5 ; \quad 2.5-5 ; 5-50 ; 50-75 ;$ 75-100; 100-125; $125-150 ;>150)$

Pathogenic, morphological, and fumigant sensitivity ranges were also analyzed using a numerical taxonomy and multivariate analysis system NTSYS-pc version 2.10b (Exeter Software, Setauket, New York, U.S.A.) (Rohlf 2002) such as is described in Villarino et al. (2016). Only morphological ranges selected by principal component analysis (PCA) using STATGRAPHICS program (Snedecor and 
Table 1. Characterization of Fusarium solani isolates: isolation source, year and geographical origin of isolation, fumigant concentration range (mg liter ${ }^{-1}$ ) to $50 \%$ growth inhibition on culture media, and sequence of a portion of the translation elongation factor- 1 alpha (EF-1 $\alpha)$ gene

\begin{tabular}{|c|c|c|c|c|c|c|c|c|}
\hline \multirow[b]{2}{*}{ Isolate } & \multirow[b]{2}{*}{$\begin{array}{c}\text { Strawberry isolation } \\
\text { source }\end{array}$} & \multirow[b]{2}{*}{$\begin{array}{l}\text { Isolation } \\
\text { year }\end{array}$} & \multirow[b]{2}{*}{ Geographical origin } & \multicolumn{4}{|c|}{$\begin{array}{c}\text { Fumigant concentration range }\left(\mathrm{mg} \mathrm{liter}^{-1}\right) \text { to } 50 \% \\
\text { growth inhibition }\end{array}$} & \multirow[b]{2}{*}{$\begin{array}{l}E F-1 \alpha \text { GenBank } \\
\text { accession no. }\end{array}$} \\
\hline & & & & Dazomet & $\begin{array}{l}\text { Metam } \\
\text { sodium }\end{array}$ & Chloropicrin & $\begin{array}{c}\text { 1,3- } \\
\text { Dichloropropene }\end{array}$ & \\
\hline MA & Nursery plant & 2015 & $\begin{array}{l}\text { Navalmanzano, } \\
\text { Segovia, Spain }\end{array}$ & $0-0.25$ & $0-0.25$ & $2.5-5$ & $>150$ & MH300515 \\
\hline MAA & Nursery plant & 2015 & $\begin{array}{l}\text { Navalmanzano, } \\
\text { Segovia, Spain }\end{array}$ & $0-0.25$ & $125-150$ & $5-50$ & $>150$ & MH300518 \\
\hline MAB & Nursery plant & 2015 & $\begin{array}{l}\text { Navalmanzano, } \\
\text { Segovia, Spain }\end{array}$ & $0-0.25$ & $125-150$ & $5-50$ & $>150$ & MH300526 \\
\hline MAC & Nursery plant & 2015 & $\begin{array}{l}\text { Navalmanzano, } \\
\text { Segovia, Spain }\end{array}$ & $5-50$ & $0.25-0.5$ & $0.25-0.5$ & $125-150$ & MH300522 \\
\hline MAD & Nursery plant & 2015 & $\begin{array}{l}\text { Navalmanzano, } \\
\text { Segovia, Spain }\end{array}$ & $5-50$ & $0-0.25$ & $5-50$ & $>150$ & MH300511 \\
\hline MAE & Nursery soil & 2016 & Arévalo, Ávila, Spain & $5-50$ & $50-75$ & $5-50$ & $>150$ & MH300534 \\
\hline MAF & Nursery soil & 2016 & $\begin{array}{l}\text { Navalmanzano, } \\
\text { Segovia, Spain }\end{array}$ & $5-50$ & $0-0.25$ & $50-75$ & $>150$ & MH300535 \\
\hline MAG & Nursery soil & 2016 & $\begin{array}{l}\text { Navalmanzano, } \\
\text { Segovia, Spain }\end{array}$ & $5-50$ & $100-125$ & $5-50$ & $>150$ & MH300540 \\
\hline MAH & Nursery soil & 2016 & $\begin{array}{l}\text { Navalmanzano, } \\
\text { Segovia, Spain }\end{array}$ & $5-50$ & $125-150$ & $5-50$ & $>150$ & MH300536 \\
\hline MAI & Nursery soil & 2016 & $\begin{array}{l}\text { Navalmanzano, } \\
\text { Segovia, Spain }\end{array}$ & $5-50$ & $50-75$ & $5-50$ & $>150$ & MH300544 \\
\hline MAJ & Nursery soil & 2016 & $\begin{array}{l}\text { Navalmanzano, } \\
\text { Segovia, Spain }\end{array}$ & $5-50$ & $50-75$ & $50-75$ & $>150$ & MH300537 \\
\hline MAK & Nursery soil & 2016 & $\begin{array}{l}\text { Navalmanzano, } \\
\text { Segovia, Spain }\end{array}$ & $5-50$ & $50-75$ & $50-75$ & $>150$ & MH300541 \\
\hline MAL & Nursery plant & 2016 & $\begin{array}{l}\text { Navalmanzano, } \\
\text { Segovia, Spain }\end{array}$ & $5-50$ & $50-75$ & $5-50$ & $>150$ & MH300504 \\
\hline MAM & Nursery plant & 2016 & $\begin{array}{l}\text { Navalmanzano, } \\
\text { Segovia, Spain }\end{array}$ & $5-50$ & $75-100$ & $5-50$ & - & MH300506 \\
\hline MAN & Nursery plant & 2016 & $\begin{array}{l}\text { Navalmanzano, } \\
\text { Segovia, Spain }\end{array}$ & $5-50$ & $50-75$ & $5-50$ & $>150$ & MH300507 \\
\hline MAO & Nursery soil & 2016 & $\begin{array}{l}\text { Navalmanzano, } \\
\text { Segovia, Spain }\end{array}$ & $5-50$ & $50-75$ & $50-75$ & $>150$ & MH300532 \\
\hline MAP & Nursery soil & 2016 & $\begin{array}{l}\text { Navalmanzano, } \\
\text { Segovia, Spain }\end{array}$ & $0-0.25$ & $50-75$ & $5-50$ & $>150$ & MH300538 \\
\hline MAQ & Nursery soil & 2016 & $\begin{array}{l}\text { Navalmanzano, } \\
\text { Segovia, Spain }\end{array}$ & $5-50$ & $75-100$ & $50-75$ & $>150$ & MH300531 \\
\hline MAR & Nursery soil & 2016 & $\begin{array}{l}\text { Navalmanzano, } \\
\text { Segovia, Spain }\end{array}$ & $50-75$ & $50-75$ & $5-50$ & $>150$ & MH300530 \\
\hline MAS & Nursery soil & 2016 & $\begin{array}{l}\text { Navalmanzano, } \\
\text { Segovia, Spain }\end{array}$ & $50-75$ & $50-75$ & $5-50$ & $>150$ & MH300545 \\
\hline MAT & Nursery soil & 2016 & $\begin{array}{l}\text { Navalmanzano, } \\
\text { Segovia, Spain }\end{array}$ & $50-75$ & $0-0.25$ & $0-0.25$ & $>150$ & MH300543 \\
\hline MAV & Nursery soil & 2016 & $\begin{array}{l}\text { Navalmanzano, } \\
\text { Segovia, Spain }\end{array}$ & $5-50$ & $0.25-0.5$ & $5-50$ & $>150$ & MH300503 \\
\hline MAW & Nursery soil & 2016 & $\begin{array}{l}\text { Navalmanzano, } \\
\text { Segovia, Spain }\end{array}$ & $5-50$ & $50-75$ & $5-50$ & $>150$ & MH300542 \\
\hline MAX & Nursery soil & 2016 & $\begin{array}{l}\text { Navalmanzano, } \\
\text { Segovia, Spain }\end{array}$ & $50-75$ & $125-150$ & $75-100$ & $>150$ & MH300529 \\
\hline MAY & Nursery soil & 2016 & $\begin{array}{l}\text { Navalmanzano, } \\
\text { Segovia, Spain }\end{array}$ & $5-50$ & $75-100$ & $5-50$ & $>150$ & MH300528 \\
\hline MAZ & Nursery soil & 2016 & $\begin{array}{l}\text { Navalmanzano, } \\
\text { Segovia, Spain }\end{array}$ & $5-50$ & $75-100$ & $50-75$ & $>150$ & MH300539 \\
\hline MB & Nursery soil & 2016 & Arévalo, Ávila, Spain & $5-50$ & $125-150$ & - & - & MH300501 \\
\hline MBA & Nursery soil & 2016 & $\begin{array}{l}\text { Navalmanzano, } \\
\text { Segovia, Spain }\end{array}$ & $5-50$ & $50-75$ & $5-50$ & $>150$ & MH300527 \\
\hline MBB & Nursery soil & 2016 & $\begin{array}{l}\text { Navalmanzano, } \\
\text { Segovia, Spain }\end{array}$ & - & $>150$ & $0.25-0.5$ & $>150$ & MH300505 \\
\hline $\mathrm{MBC}$ & Nursery soil & 2016 & $\begin{array}{l}\text { Navalmanzano, } \\
\text { Segovia, Spain }\end{array}$ & $50-75$ & $50-75$ & $50-75$ & $>150$ & \\
\hline MF & Nursery plant & 2015 & $\begin{array}{l}\text { Navalmanzano, } \\
\text { Segovia, Spain }\end{array}$ & $5-50$ & $50-75$ & $0.25-0.5$ & $>150$ & MH300510 \\
\hline MG & Nursery plant & 2015 & $\begin{array}{l}\text { Navalmanzano, } \\
\text { Segovia, Spain }\end{array}$ & $5-50$ & $0.25-0.5$ & $0.25-0.5$ & $>150$ & MH300514 \\
\hline MGN & Nursery soil & 2016 & Arévalo, Ávila, Spain & $5-50$ & $125-150$ & $0.25-0.5$ & $>150$ & MH300502 \\
\hline MH & Nursery plant & 2015 & $\begin{array}{l}\text { Navalmanzano, } \\
\text { Segovia, Spain }\end{array}$ & $5-50$ & $5-50$ & $0.25-0.5$ & $>150$ & MH300521 \\
\hline
\end{tabular}


Table 1. (Continued from previous page)

Fumigant concentration range $\left(\mathrm{mg} \mathrm{liter}^{-1}\right)$ to $\mathbf{5 0 \%}$

growth inhibition

\begin{tabular}{|c|c|c|c|c|c|c|c|c|}
\hline Isolate & $\begin{array}{c}\text { Strawberry isolation } \\
\text { source }\end{array}$ & $\begin{array}{l}\text { Isolation } \\
\text { year }\end{array}$ & Geographical origin & Dazomet & $\begin{array}{l}\text { Metam } \\
\text { sodium }\end{array}$ & Chloropicrin & $\begin{array}{c}\text { 1,3- } \\
\text { Dichloropropene }\end{array}$ & $\begin{array}{c}E F-1 \alpha \text { GenBank } \\
\text { accession no. }\end{array}$ \\
\hline$\overline{\mathrm{MI}}$ & Nursery soil & 2015 & $\begin{array}{l}\text { Navalmanzano, } \\
\text { Segovia, Spain }\end{array}$ & $5-50$ & $50-75$ & $0.25-0.5$ & $>150$ & MH300513 \\
\hline MJ & Nursery plant & 2011 & Arévalo, Ávila, Spain & $5-50$ & $50-75$ & $0.25-0.5$ & $>150$ & МН300509 \\
\hline MK & Nursery plant & 2015 & $\begin{array}{l}\text { Navalmanzano, } \\
\text { Segovia, Spain }\end{array}$ & $5-50$ & $75-100$ & $0.25-0.5$ & $>150$ & МH300519 \\
\hline ML & Nursery soil & 2016 & Arévalo, Ávila, Spain & $5-50$ & $50-75$ & $0-0.25$ & - & МH300508 \\
\hline MM & Nursery soil & 2016 & Arévalo, Ávila, Spain & $5-50$ & $5-50$ & $5-50$ & $>150$ & МH300533 \\
\hline $\mathrm{MN}$ & Nursery soil & 2016 & Arévalo, Ávila, Spain & $5-50$ & $75-100$ & $0-0.25$ & - & МН300499 \\
\hline MO & Nursery soil & 2016 & Arévalo, Ávila, Spain & $5-50$ & $50-75$ & $0.25-0.5$ & $>150$ & MH300500 \\
\hline MP & Nursery soil & 2016 & Arévalo, Ávila, Spain & $5-50$ & - & $0.25-0.5$ & $>150$ & МН300497 \\
\hline MQ & Nursery soil & 2016 & Arévalo, Ávila, Spain & $5-50$ & $125-150$ & $0.25-0.5$ & $125-150$ & МН300498 \\
\hline MR & Nursery plant & 2015 & $\begin{array}{l}\text { Navalmanzano, } \\
\text { Segovia, Spain }\end{array}$ & $0-0.25$ & $50-75$ & $0.25-0.5$ & $>150$ & MH300524 \\
\hline MS & Nursery plant & 2015 & $\begin{array}{l}\text { Navalmanzano, } \\
\text { Segovia, Spain }\end{array}$ & $5-50$ & $0-0.25$ & $0.5-2.5$ & $>150$ & МH300523 \\
\hline MT & Nursery plant & 2015 & $\begin{array}{l}\text { Navalmanzano, } \\
\text { Segovia, Spain }\end{array}$ & $0-0.25$ & $0-0.25$ & - & $>150$ & МH300525 \\
\hline MU & Nursery plant & 2011 & Arévalo, Ávila, Spain & $5-50$ & $125-150$ & $5-50$ & $>150$ & МН300516 \\
\hline MV & Nursery plant & 2011 & Arévalo, Ávila, Spain & $50-75$ & $75-100$ & $5-50$ & $>150$ & MH300520 \\
\hline MY & Nursery plant & 2016 & Arévalo, Ávila, Spain & $0-0.25$ & $0-0.25$ & $5-50$ & $125-150$ & МH300517 \\
\hline MZ & Nursery plant & 2016 & Arévalo, Ávila, Spain & $100-125$ & - & $5-50$ & $>150$ & МН300512 \\
\hline TOR-1 & Fruit production soil & 2010 & Moguer, Huelva, Spain & $5-50$ & $50-75$ & $0-0.25$ & $125-150$ & KF275034 \\
\hline TOR-7 & Fruit production soil & 2010 & Moguer, Huelva, Spain & $5-50$ & $50-75$ & $0-0.25$ & $0-0.25$ & KY486705 \\
\hline TOR-397 & Fruit production soil & 2012 & Moguer, Huelva, Spain & $5-50$ & $5-50$ & $5-50$ & $>150$ & KX215049 \\
\hline TOR-725 & Fruit production soil & 2012 & Moguer, Huelva, Spain & $50-75$ & $125-150$ & $0.5-2.5$ & $125-150$ & $\mathrm{KX} 215050$ \\
\hline AB-G1 & Fruit production soil & 2014 & Moguer, Huelva, Spain & $5-50$ & $50-75$ & $50-75$ & $>150$ & KY486691 \\
\hline AB-D4 & Fruit production soil & 2014 & Moguer, Huelva, Spain & $50-75$ & $50-75$ & $5-50$ & $>150$ & KY486690 \\
\hline $\mathrm{AB}-\mathrm{C} 2$ & Fruit production soil & 2014 & Moguer, Huelva, Spain & $5-50$ & $5-50$ & $5-50$ & $>150$ & KY486688 \\
\hline AB-D2 & Fruit production soil & 2014 & Moguer, Huelva, Spain & $5-50$ & $5-50$ & $5-50$ & $125-150$ & KY486689 \\
\hline DB-A1 & Fruit production soil & 2014 & Moguer, Huelva, Spain & $5-50$ & $5-50$ & $50-75$ & $>150$ & KY486692 \\
\hline DB-C2 & Fruit production soil & 2014 & Moguer, Huelva, Spain & $5-50$ & $5-50$ & - & $>150$ & KY486693 \\
\hline DB-F3 & Fruit production soil & 2014 & Moguer, Huelva, Spain & $5-50$ & $5-50$ & $0-0.25$ & $0-0.25$ & KY486694 \\
\hline DB-G1 & Fruit production soil & 2014 & Moguer, Huelva, Spain & $50-75$ & $50-75$ & $5-50$ & $>150$ & KY486695 \\
\hline OCCI-C1 & Fruit production soil & 2014 & Moguer, Huelva, Spain & - & - & - & - & KY486696 \\
\hline Fs-1S & Fruit production soil & 2014 & Almonte, Huelva, Spain & $50-75$ & $125-150$ & $2.5-5$ & $>150$ & KY486652 \\
\hline Fs-2S & Fruit production soil & 2014 & Moguer, Huelva, Spain & $5-50$ & $5-50$ & $0-0.25$ & $>150$ & KY486653 \\
\hline Fs-4S & Fruit production soil & 2014 & Moguer, Huelva, Spain & $5-50$ & $50-75$ & $5-50$ & $125-150$ & KY486654 \\
\hline Fs-10S & Fruit production soil & 2014 & Moguer, Huelva, Spain & $5-50$ & $5-50$ & $0.5-2.5$ & - & KY486655 \\
\hline Fs-19S & Fruit production soil & 2014 & Moguer, Huelva, Spain & $5-50$ & $5-50$ & $50-75$ & $>150$ & KY486657 \\
\hline Fs-22S & Fruit production soil & 2014 & $\begin{array}{l}\text { Lucena del Puerto, } \\
\text { Huelva, Spain }\end{array}$ & $50-75$ & $50-75$ & $5-50$ & $>150$ & KY486658 \\
\hline Fs-23S & Fruit production soil & 2014 & Moguer, Huelva, Spain & $0-0.25$ & $5-50$ & $2.5-5$ & - & KY486659 \\
\hline Fs-32S & Fruit production soil & 2014 & Bonares, Huelva, Spain & $50-75$ & $125-150$ & $5-50$ & $>150$ & KY486660 \\
\hline Fs-35S & Fruit production soil & 2014 & Bonares, Huelva, Spain & $5-50$ & $5-50$ & $5-50$ & $>150$ & KY486661 \\
\hline Fs-40S & Fruit production soil & 2014 & Moguer, Huelva, Spain & $5-50$ & $5-50$ & $0.5-2.5$ & $0-0.25$ & KY486663 \\
\hline Fs- $52 \mathrm{~S}$ & Fruit production soil & 2014 & Moguer, Huelva, Spain & $50-75$ & $50-75$ & $5-50$ & $125-150$ & KY486668 \\
\hline Fs-54S & Fruit production soil & 2014 & Moguer, Huelva, Spain & $5-50$ & $75-100$ & $5-50$ & - & KY486670 \\
\hline Fs-57S & Fruit production soil & 2014 & Moguer, Huelva, Spain & $0-0.25$ & - & - & $>150$ & KY486673 \\
\hline Fs-70S & Fruit production soil & 2015 & Moguer, Huelva, Spain & $2.5-5$ & $50-75$ & $5-50$ & - & KY486674 \\
\hline TOR-11 & Fruit production plant & 2010 & Moguer, Huelva, Spain & $5-50$ & $5-50$ & $5-50$ & $125-150$ & KF275033 \\
\hline TOR-393 & Fruit production plant & 2012 & Moguer, Huelva, Spain & $5-50$ & $0.5-2.5$ & $5-50$ & $>150$ & KX215048 \\
\hline FPOST-164 & Fruit production plant & 2013 & Cartaya, Huelva, Spain & $50-75$ & $125-150$ & $5-50$ & $125-150$ & KX215052 \\
\hline FPOST-169 & Fruit production plant & 2013 & Cartaya, Huelva, Spain & $50-75$ & $125-150$ & $5-50$ & $>150$ & KX215053 \\
\hline FPOST-174 & Fruit production plant & 2013 & $\begin{array}{l}\text { Palos de la Frontera, } \\
\text { Huelva, Spain }\end{array}$ & $0-0.25$ & - & $5-50$ & $>150$ & KX215054 \\
\hline FPOST-176 & Fruit production plant & 2013 & Cartaya, Huelva, Spain & $5-50$ & $50-75$ & $5-50$ & $>150$ & KX215055 \\
\hline FPOST-81 & Fruit production plant & 2012 & Cartaya, Huelva, Spain & - & $50-75$ & $0-0.25$ & $>150$ & KF275032 \\
\hline E-III & Fruit production plant & 2014 & Cartaya, Huelva, Spain & - & - & - & - & KX215056 \\
\hline Fs-1P & Fruit production plant & 2015 & Almonte, Huelva, Spain & $5-50$ & $50-75$ & $5-50$ & - & KY486675 \\
\hline Fs-67P & Fruit production plant & 2015 & Moguer, Huelva, Spain & $5-50$ & $5-50$ & $5-50$ & - & KY486676 \\
\hline Fs-71P & Fruit production plant & 2015 & Moguer, Huelva, Spain & $50-75$ & $50-75$ & - & $>150$ & KY486678 \\
\hline Fs-76P & Fruit production plant & 2015 & Moguer, Huelva, Spain & $5-50$ & $50-75$ & $0.5-2.5$ & $0-0.25$ & KY486679 \\
\hline Fs-145P & Fruit production plant & 2015 & Moguer, Huelva, Spain & $50-75$ & $50-75$ & $5-50$ & $>150$ & KY486682 \\
\hline Fs-147P & Fruit production plant & 2015 & Cartaya, Huelva, Spain & $50-75$ & $50-75$ & $5-50$ & $>150$ & $\begin{array}{c}\text { KY486684 } \\
\text { nued on next p }\end{array}$ \\
\hline
\end{tabular}


Cochran 1980) were used in numerical taxonomy and multivariate analysis.

\section{Results}

Pathogenicity test. Some $F$. solani isolates caused visible symptoms such as yellowing of older leaves and wilting and death on strawberry plants. Stunting was also evident on infected plants as a decrease in plant weight. No symptoms were observed on all uninoculated plants.

Significant differences in disease severity were observed among the $101 \mathrm{~F}$. solani isolates. Based on presence or absence of stunting, the tested isolates grouped into two clusters (Fig. 1, $r=0.91$ ). The results showed the existence of 63 nonpathogenic isolates from both Spanish strawberry areas (NP, 62.37\%). Most F. solani were nonpathogenic isolates recovered from the soils of the two Spanish strawberry areas $(66 \%)$.

Only $38 F$. solani isolates $(37.62 \%)$ caused disease on strawberry plants under controlled conditions (Fig. 1), showing variability of Fusarium symptoms (Fig. 2; $r=0.95$ ). Of these 38 pathogenic strains, 18 isolates were from nurseries and 20 isolates from fruit production fields (Fig. 2). According to the isolation origin, 23 and 15 pathogenic isolates from plant and soil were obtained, respectively. Almost $70 \%$ of these pathogenic strains gave rise to stunted inoculated plants and $34.21 \%$ showed disease symptoms (Fig. 2). There were $13 \mathrm{~F}$. solani isolates that caused stunting but not disease severity, and all of them were recovered from both Spanish strawberry areas diseased plants except isolate MAR_S from a strawberry nursery soil (Fig. 2). No relationship was found between pathogenic ranges and isolation origin (soil and plant).

Most of the pathogenic isolates (50\%) showed slight severity (SP $<25 \%$ ), mainly from nursery soils. Isolates clustered as high severity $(\mathrm{HP}>50 \%)$ (one isolate) and moderate $(\mathrm{MP}=25$ to $50 \%$ ) (four isolates) only came from fruit production field soils and plants (13.15\%) (Fig. 2).

Cultural and morphological characterization. Cultural and morphological characterizations were carried out with 103 F. solani isolates from both Spanish strawberry areas.

Colony diameter showed variation between $F$. solani isolates. The minimum growth at 7 days of incubation was between 4.5 and $5 \mathrm{~cm}$ from nursery isolates, and between 5 and $5.5 \mathrm{~cm}$ from fruit production fields, where both ranges were significant. On the contrary, isolates reached a maximum growth of 7.71 to $8.12 \mathrm{~cm}$ from fruit production fields and nurseries, respectively. No significant differences were observed on these maximum growths. All isolates showed a growth rate ranging from 0.7 to $1 \mathrm{~cm} \mathrm{day}^{-1}$ on PDA at $25^{\circ} \mathrm{C}$ (data not shown).

Macroconidia were present on culture media with most isolates with some exceptions. Out of 50 isolates analyzed from nurseries, only five with white color on front of the colony did not present macroconidia (ML_S, MAL_P, MAM_P, MAN_P, and MAV_S).
However, only three isolates with cream color on front of the colony from fruit production fields did not present macroconidia (EC-1P_P, Fs-23S_S, and Fs-40S_S). On the other hand, microconidia existed in all $F$. solani isolates. Chlamydospores were present in all isolates from both areas, except in five from nurseries (MA_P, MAC_P, MP S, MR_P, and MV_P) and eight from fruit production fields (FPOST-174_P, Fs-23S_S, Fs-32S_S, Fs-35S_S, Fs-40S_S, Fs52S_S, Fs-57S_S, and TOR-397_S).

All isolates showed a wide variation with respect to the colony color, and pigmentation of the top view of the colony varied from white to yellow, while the colony reverse side showed colors from white to dark orange. Most isolates from fruit production fields showed cream color on the front $(94.3 \%)$ and on the back of the colony $(47.1 \%)$. However, most isolates from nurseries showed white color on the front (52\%) and cream (36\%) or pink (32\%) color on the back of the colony. Yellow color on the front of colonies or cream color on the back of colonies was only observed in $F$. solani isolates from strawberry nurseries.

The results of the PCA revealed that the mycelial color and the presence or absence of macroconidia were the most important morphological variables that distinguished Spanish $F$. solani populations with $86.85 \%$ weight in variability (Fig. 3). Components 1 , 2, and 3 explained $36.24,28.45$, and $21.50 \%$ of the variance, respectively. Based on these characteristics, both Spanish strawberry populations were separated according to the presence or absence of macroconidia and colony color as shown in Figure $4(r=0.87)$.

F. solani pathogenic populations (38 isolates) from both Spanish strawberry production areas also showed clear differences between them according to the colony's front color and the presence of macroconidia, with the exception of two isolates from nurseries (MAC_P and MS_P) and two isolates from fruit production fields (Fs-4S_S and EC-1P_P) (Fig. 5; $r=0.94$ ). Almost all pathogenic isolates presented macroconidia, except four isolates from nurseries (MAL_P, MAM_P, MAN_P, and MAV_S) and one from fruit production fields (EC-1P_P), or chlamydospores, except three isolates from nurseries (MS_P, MAC_P, MAP_S) and two from fruit production fields (FPOST-174P_P and TOR-397_S) (Fig. 5). All pathogenic isolates from fruit fields were cream colored on the front of the colony except Fs-4S_S (pink), while all different colors were present on pathogenic isolates from nurseries. All colors were presented on the back of colonies from both Spanish areas, except white color did not appear on the back colony of these pathogenic isolates.

Fumigant sensitivity tests. Dazomet concentration range of 5-50 ppm inhibited 50\% growth of most $F$. solani isolates from strawberry nurseries, while a higher concentration of this product was needed to achieve $50 \%$ inhibition of growth on $F$. solani isolates from the fruit production fields, with the exception of isolates that inhibited their growth at concentrations lower than $0.25 \mathrm{ppm}$ in both areas (Table 1).

The doses of metam sodium that inhibited $50 \%$ of the growth ranged between 50 and $100 \mathrm{ppm}$ for isolates from nurseries and

Table 1. (Continued from previous page)

\begin{tabular}{|c|c|c|c|c|c|c|c|c|}
\hline \multirow[b]{2}{*}{ Isolate } & \multirow[b]{2}{*}{$\begin{array}{l}\text { Strawberry isolation } \\
\text { source }\end{array}$} & \multirow[b]{2}{*}{$\begin{array}{l}\text { Isolation } \\
\text { year }\end{array}$} & \multirow[b]{2}{*}{ Geographical origin } & \multicolumn{4}{|c|}{$\begin{array}{c}\text { Fumigant concentration range }\left(\mathrm{mg} \mathrm{liter}^{-1}\right) \text { to } 50 \% \\
\text { growth inhibition }\end{array}$} & \multirow[b]{2}{*}{$\begin{array}{l}E F-1 \alpha \text { GenBank } \\
\text { accession no. }\end{array}$} \\
\hline & & & & Dazomet & $\begin{array}{l}\text { Metam } \\
\text { sodium }\end{array}$ & Chloropicrin & $\begin{array}{c}\text { 1,3- } \\
\text { Dichloropropene }\end{array}$ & \\
\hline $\mathrm{CH}-1 \mathrm{P}$ & Fruit production plant & 2016 & Chipiona, Cádiz, Spain & - & $50-75$ & - & $0-0.25$ & KY486697 \\
\hline $\mathrm{CH}-2 \mathrm{P}$ & Fruit production plant & 2016 & Chipiona, Cádiz, Spain & $5-50$ & $50-75$ & $50-75$ & $>150$ & KY486698 \\
\hline $\mathrm{CH}-3 \mathrm{P}$ & Fruit production plant & 2016 & Chipiona, Cádiz, Spain & $0-0.25$ & $5-50$ & $5-50$ & - & KY486699 \\
\hline $\mathrm{CH}-4 \mathrm{P}$ & Fruit production plant & 2016 & Chipiona, Cádiz, Spain & $5-50$ & $50-75$ & $5-50$ & $125-150$ & KY486700 \\
\hline CH-5P & Fruit production plant & 2016 & Chipiona, Cádiz, Spain & $50-75$ & $50-75$ & - & $0-0.25$ & KY486701 \\
\hline CH-6P & Fruit production plant & 2016 & Chipiona, Cádiz, Spain & $5-50$ & $75-100$ & - & $0-0.25$ & KY486702 \\
\hline EC-1P & Fruit production plant & 2016 & Moguer, Huelva, Spain & $75-100$ & $50-75$ & $0-0.25$ & - & KY486703 \\
\hline $\mathrm{EC}-2 \mathrm{P}$ & Fruit production plant & 2016 & Moguer, Huelva, Spain & $5-50$ & $5-50$ & - & $>150$ & KY486704 \\
\hline Fs-143P & Fruit production plant & 2015 & Cartaya, Huelva, Spain & - & $50-75$ & - & $0-0.25$ & KY486680 \\
\hline Fs- $144 \mathrm{P}$ & Fruit production plant & 2015 & Cartaya, Huelva, Spain & $50-75$ & $50-75$ & $5-50$ & - & KY486681 \\
\hline Fs-150P & Fruit production plant & 2015 & Chipiona, Cádiz, Spain & - & - & - & - & KY486687 \\
\hline Fs-152P & Fruit production plant & 2016 & Chipiona, Cádiz, Spain & - & - & - & - & \\
\hline
\end{tabular}


between 5 and $75 \mathrm{ppm}$ for isolates from fruit production fields. There were 20 isolates from nurseries that inhibited their growth at lower $(<0.25 \mathrm{ppm})$ and higher concentrations ( $>75 \mathrm{ppm})$ (Table 1).

However, most of the $F$. solani isolates growth was inhibited by low chloropicrin concentrations. No $F$. solani isolate grew at concentration greater than $75 \mathrm{ppm}$. Particularly, the concentration of $0.25-0.5 \mathrm{ppm}$ of this fumigant inhibited the growth of 13 isolates from nurseries (Table 1).

On the other hand, F. solani isolate growth was only inhibited at 1,3-dichloropropene concentrations up to $125 \mathrm{ppm}$. There were only eight $F$. solani isolates from fruit production fields that showed growth inhibition at concentrations below $0.25 \mathrm{ppm}$.

\section{Discussion}

Pathogenic and morphology variability and sensitivity to fumigants of $F$. solani isolates from soils and strawberry plants from both
Spanish strawberry populations have been studied. The presence of $F$. solani was recently detected for the first time in the area of Huelva, as a pathogen causing stunting, wilting, necrosis, and death in strawberry plants (Pastrana et al. 2014). F. solani was also detected in 2012 in strawberry nursery plants with symptoms of crown rot (Redondo et al. 2012). F. solani also has been described as soil-borne fungal pathogen to several crops in Spain (Pastrana et al. 2017). F. solani caused different disease incidence on a great host range with diversity of colony morphology (Brasileiro et al. 2004).

The majority of $F$. solani isolates studied in both Spanish strawberry areas was not pathogenic $(62 \%)$. Only $38 \mathrm{~F}$. solani isolates $(37.62 \%)$ caused Fusarium wilt on strawberry plants under controlled conditions. $F$. solani usually persists and survives in soil for a long time, and some strains may become pathogenic or nonpathogenic (Bahar and Shahab 2012). F. solani and other Fusarium spp. include different biological groups such as endophytes (Leslie et al. 1990),

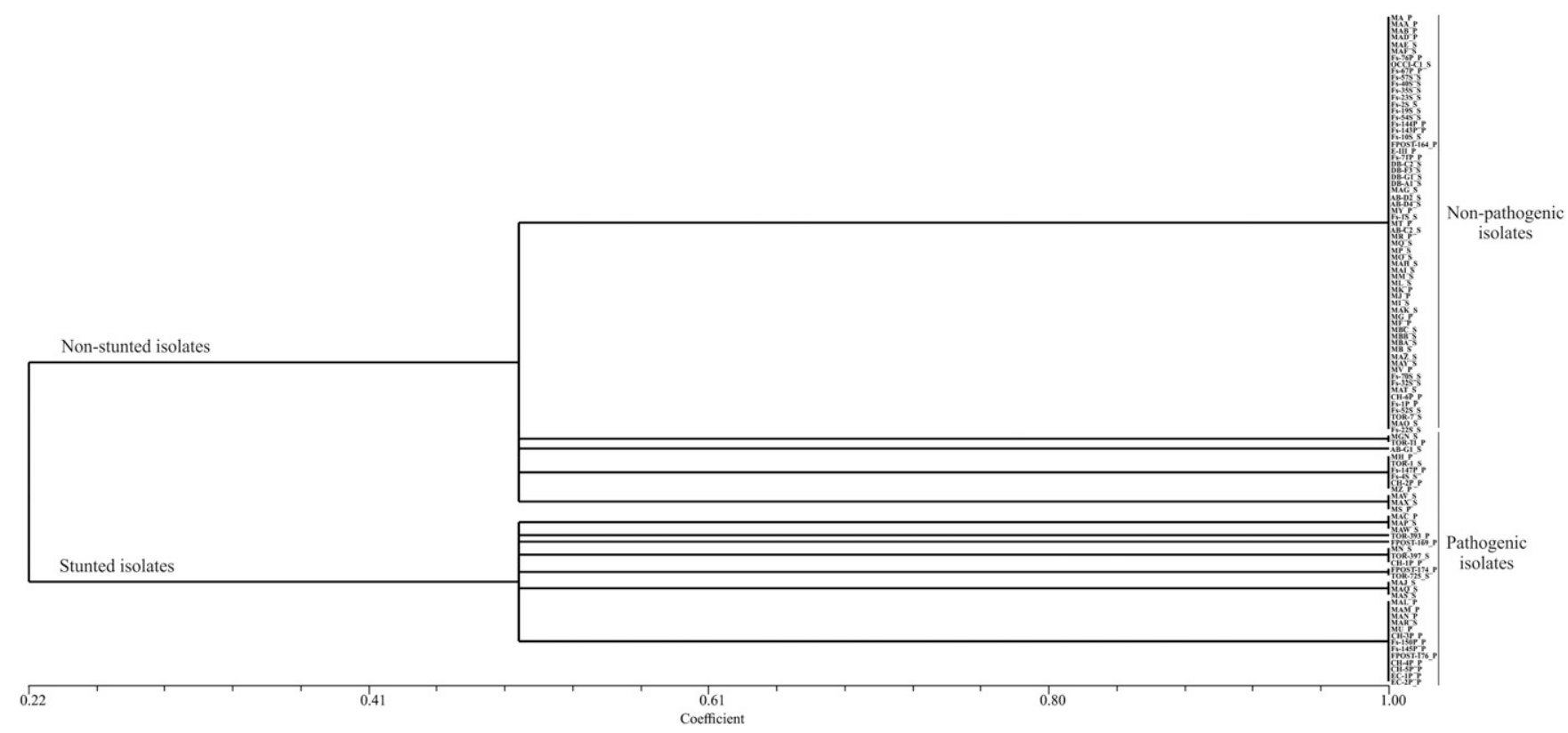

Fig. 1. UPGMA (unweighted pair-group method with arithmetic average) dendrogram generated from the severity disease and plant weight on plants infected with each of the 101 isolates of Fusarium solani. The UPGMA tree was generated using the SAHN (sequential, agglomerative, hierarchical, and nested) clustering program (NTSYS-pc version 2.10b) after calculating the simple matching (SM) coefficient. The cophenetic coefficient, $r=0.91$. Isolation source: soil (_S); diseased plant (_P).

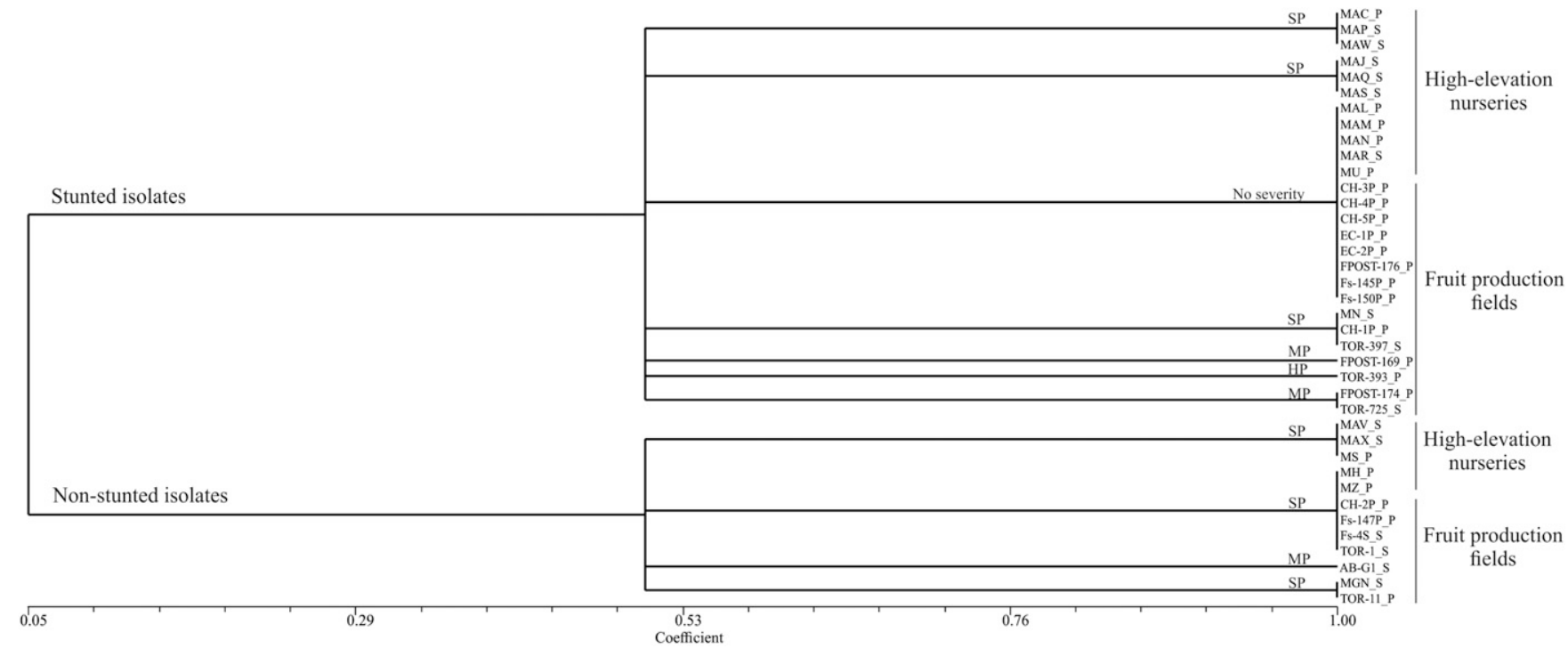

Fig. 2. UPGMA (unweighted pair-group method with arithmetic average) dendrogram generated from combined severity disease and plant weight data. Plants were infected with each of the 38 pathogenic isolates of Fusarium solani. The UPGMA tree was inferred using the SAHN (sequential, agglomerative, hierarchical, and nested) clustering program (NTSYS-pc version 2.10b) after calculating the simple matching (SM) coefficient. The cophenetic coefficient, $r=0.95$. Pathogenicity categories of isolates were: HP: highly pathogenic, MP: moderately pathogenic, and SP: slightly pathogenic. Isolation source: soil (_S); diseased plant (_P). 
saprophytes (Bushelman et al. 1995; Fracchia et al. 2000), opportunists (Alves-Santos et al. 2002), and plant pathogens (Chandra et al. 2011), with a high level of polymorphism inside them (AlvesSantos et al. 1999). Pathogenic strains of Fusarium spp. can come from nonpathogenic strains, and vice versa, due to mutations in a few genes (Baayen et al. 2000).

Most $F$. solani pathogenic isolates from Spanish strawberry areas showed low severity $(52.63 \%)$ on strawberry plants under controlled conditions, mainly those from nursery soils. The most pathogenic isolates came from diseased plants from fruit production fields. However, in both Spanish strawberry areas, $F$. solani seemed a weak pathogen, which caused mostly low wilting and stunting. Pathogenicity of $F$. solani isolates obtained from plants was more variable than that of those isolated from soils: more than $50 \%$ of pathogenic isolates came from plants, especially those causing only stunting. Almost $70 \%$ of pathogenic isolates caused stunting in strawberry plants in

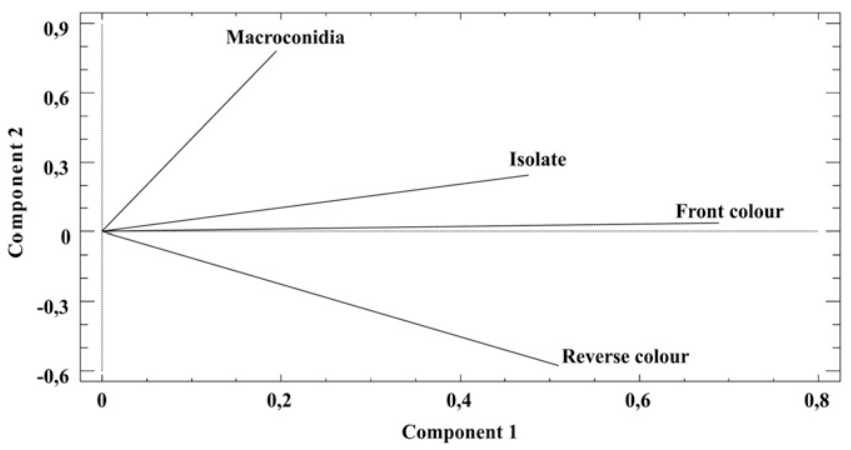

Fig. 3. Principal component analysis (PCA) of the morphological data from the $103 \mathrm{~F}$. solani isolates growing on potato dextrose agar (PDA). PCA showed the main factors that differentiated both Spanish Fusarium solani populations. Components 1, 2, and 3 accounted for $36.24,28.45$, and $21.50 \%$ of the variance, respectively. the tests carried out under controlled conditions. Stunting usually was the most pronounced symptom in in vitro tests against $F$. solani, reducing fresh plant weight (Pastrana et al. 2017).

On the other hand, both Spanish $F$. solani populations were morphologically different. The morphological characteristics that best explain the $F$. solani variability ( $86.85 \%$ weight in the variability) were the colony color and the presence of macroconidia on culture medium which divided both Spanish strawberry areas into two different clusters. $F$. solani isolates from fruit production fields presented mostly macroconidia on culture and showed cream color on the front of the colonies, while the $F$. solani population from plant nurseries presented some isolates without macroconidia (16\%) and their colonies showed variable colors (white, yellow, pink). F. solani pathogenic isolates (38 isolates) from both Spanish strawberry production areas also showed clear differences between them according to the colony's front color and the presence of macroconidia. These characteristics have already been used for the differentiation of Fusarium spp. (Albores et al. 2014). No relationship among presence of macroconidia or chlamydospores on culture media and pathogenesis of each Spanish strawberry isolates was recorded. In the same way, Berruezo et al. 2018 found notable variability in morphological characteristics and virulence in $F$. solani isolates from tobacco plants being part of the nonpathogenic strains.

The exchange of plant material from nurseries to fruit production areas does not appear to be the main source of inoculum. Currently, they are two unequal $F$. solani populations depending on Spanish strawberry production area whose origin could be their own soil or other hosts. These results confirmed those obtained by Trabelsi et al. (2017) where a source of transmission of $F$. solani isolates to several horticultural crops may be olive groves, increasing the soil-borne pathogen population (Bejarano-Alcázar et al. 1996). Therefore, Fusarium wilt control of strawberry mainly depends on soil-free pathogen in this crop and other infected hosts, since the strawberry $F$. solani isolates do not present host specificity

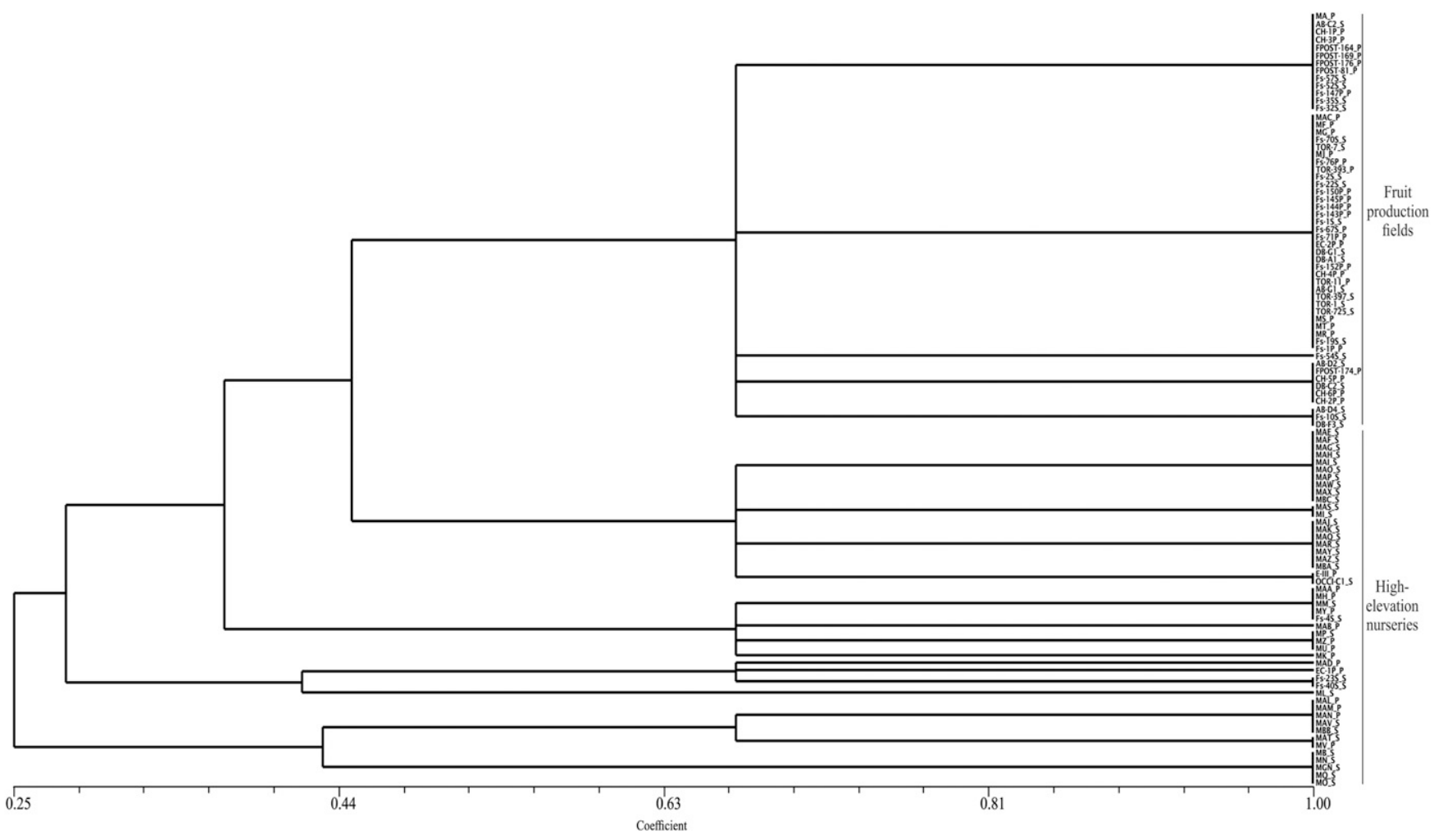

Fig. 4. UPGMA (unweighted pair-group method with arithmetic average) dendrogram inferred from the color of the front and back of the colony and the presence of macroconidia in colonies of the 103 isolates of Fusarium solani when they were grown on potato dextrose agar (PDA). The UPGMA tree was generated by the SAHN (sequential, agglomerative, hierarchical, and nested) clustering program (NTSYS-pc version 2.10b) after calculating the simple matching (SM) coefficient. The cophenetic coefficient, $r=0.87$. Isolation source: soil (_S); diseased plant (_P). 


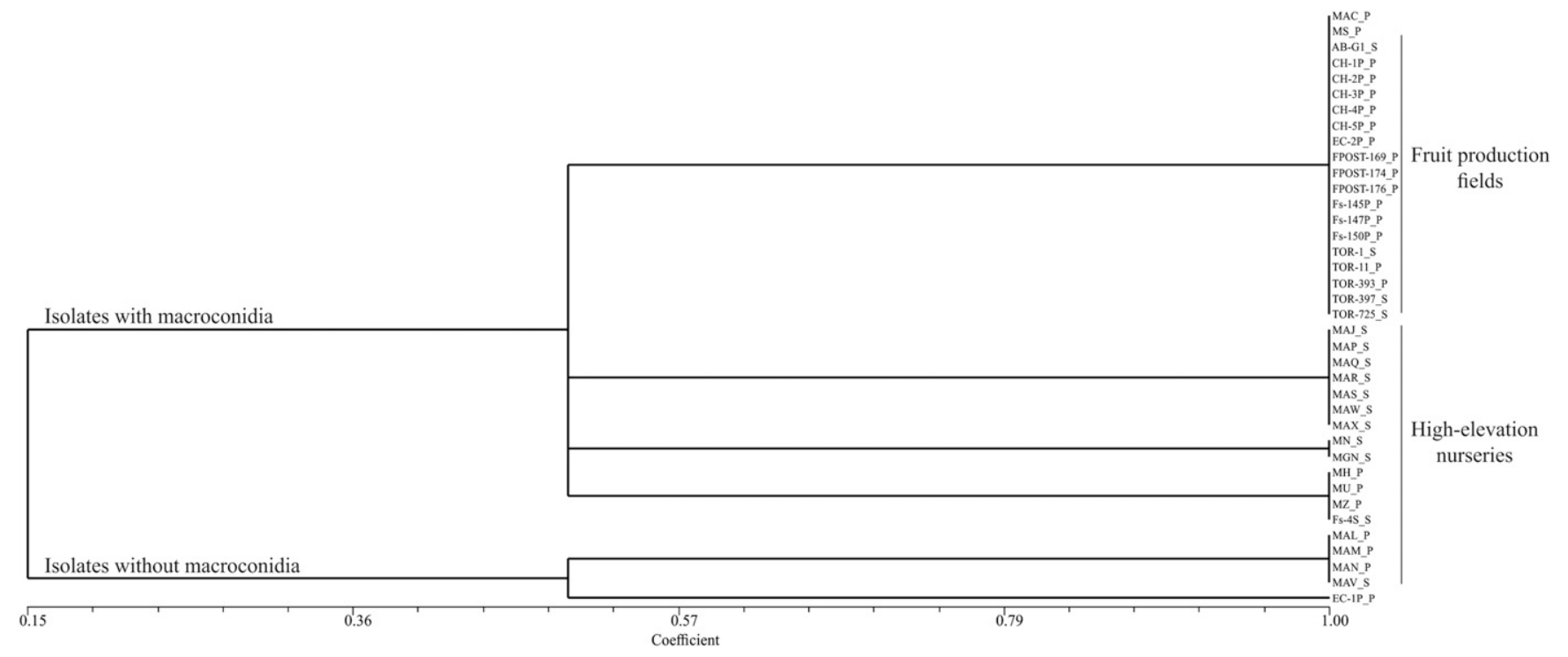

Fig. 5. UPGMA (unweighted pair-group method with arithmetic average) dendrogram inferred from the color of the front of the colony and the presence of macroconidia in colonies of the 38 pathogenic isolates of Fusarium solani when they were grown on potato dextrose agar (PDA). The UPGMA tree was generated using the sequential, agglomerative, hierarchical, and nested (SAHN) clustering program (NTSYS-pc version 2.10b) after calculating the simple matching (SM) coefficient. The cophenetic coefficient, $r=0.94$. Isolation source: soil (_S); diseased plant (_P).

and are able to infect other crops (Pastrana et al. 2017). Therefore, more knowledge of the susceptibility of rotational crops in strawberry production areas to $F$. solani would be necessary.

The strategies used against $F$. solani in other crops are usually aimed at decreasing inoculum density in the soil by fumigants, surface removal by disinfection of plant material, the use of moderately tolerant varieties (Ahmad et al. 2012; Burton et al. 2012), crop rotation (Oddino et al. 2008; Rupe et al. 1997), and biological control (Rojo et al. 2007). F. solani sensitivity to the fumigants tested was similar in the isolates from both Spanish areas, showing greater sensitivity to the field doses of dazomet and chloropicrin. However, the isolates were less sensitive to metam sodium and poorly sensitive to 1,3-dichloropropene. The main chemical alternatives to methyl bromide (MB), 1,3dichloropropene, and chloropicrin, have been banned (in the EU) since 2010 and 2013, respectively (Domínguez et al. 2014). Chloropicrin might not have been used correctly against the fungal soil pathogen since the commercial field dose was higher than necessary to control the population of $F$. solani. The same would happen with 1,3-dichloropropene, a product whose field doses were 114-146 ppm, which would be ineffective for Spanish $F$. solani isolates that showed a high resistance $(>150$ ppm) within both strawberry crop areas. Comparing the results used in the dazomet test with the doses used in the commercial fields for this biocide (137.2-196 ppm), this fumigant has proved to be an effective control strategy against $F$. solani. However, metam sodium doses used in commercial fields (43.42-91.42 ppm) were too low to control the disease, so a resistant population of $F$. solani could be developed in the soil. Although dazomet and metam sodium are soil fumigants that generate methyl-isothiocyanate (MITC) in soil, we obtained different results after its application, as in De Cal et al. 2004. Therefore, likely the ineffectiveness of metam sodium in the last years may be due to a poor distribution of the product (De Cal et al. 2004) added to an inadequate dose used in commercial fields.

The emergence and re-emergence of soil-borne pathogens in strawberry cultivation is mainly caused by the phaseout of MB and its alternative fumigants. $F$. solani as an opportunistic strawberry pathogen could have emerged in both Spanish strawberry crop areas due to the phasing out of MB and the use of reduced doses of alternative fumigants. The evolution of the populations will be subject to soil fumigants that are being used in commercial fields. The results obtained to date suggest that only dazomet at the applied doses can be effective against $F$. solani, especially taking into account that chloropicrin has been removed from the field. F. solani populations may evolve depending on the sensitivity of the products applied in each area. Biosolarization, an alternative technology to soil fumigation, combining biofumigation amended, e.g., chicken manure and soil solarization, could be also used to control Fusarium wilt of strawberry (Domínguez et al. 2014, 2016; Teruhiko et al. 2001).

\section{Acknowledgments}

M. Villarino held postdoctoral contracts that were associated to project RTA2013-00062-C05-01-E. The authors are grateful to R. Castillo, Y. Herranz, B. Larena, and M. C. Sánchez for the technical support.

\section{Literature Cited}

Ahmad, S., Zaman, N., and Khan, S. N. 2012. Response of groundnut genotypes against root rot disease in district mianwali. Pak. J. Bot. 44:383-386.

Albores, L., Baños, S., Herrera, J., Necha, L., López, M., and Hernández, A. 2014. Morphological and molecular characterization of pathogenic isolates of Fusarium spp. obtained from gladiolus corms and their sensitivity to Jatropha curcas L. oil. Afr. J. Microbiol. Res. 8:724-733.

Alves-Santos, F. M., Benito, E. P., Eslava, A. P., and Diaz-Minguez, J. M. 1999 Genetic diversity of Fusarium oxysporum strains from common bean fields in Spain. Appl. Environ. Microbiol. 65:3335-3340.

Alves-Santos, F. M., Cordeiro-Rodrigues, L., Sayagués, J. M., Martín-Domínguez, R., García-Benavides, P., Crespo, M. C., Díaz-Mínguez, J. M., and Eslava, A. P. 2002. Pathogenicity and race characterization of Fusarium oxysporum f. sp. phaseoli isolates from Spain and Greece. Plant Pathol. 51:605-611.

Anuario Estadística Agraria. 2016. Ministerio de Agricultura, Pesca y Alimentación. https://www.mapama.gob.es/es/estadistica/temas/publicaciones/ anuario-de-estadistica/

Anuario Estadística Agraria. 2017. Ministerio de Agricultura, Pesca y Alimentación. https://www.mapama.gob.es/es/estadistica/temas/publicaciones/ anuario-de-estadistica/

Arif, M., Chawla, S., Zaidi, N. W., Rayar, J. K., Variar, M., and Singh, U. S. 2012. Development of specific primers for genus Fusarium and $F$. solani using rDNA sub-unit and transcription elongation factor (TEF-1 $\alpha$ ) gene. Afr. J. Biotechnol. 11:444-447.

Arroyo, F. T., Llergo, Y., Aguado, A., and Romero, F. 2009. First report of Fusarium wilt caused by Fusarium oxysporum on strawberry in Spain. Plant Dis. 93:323.

Avilés, M., Castillo, S., Bascón, J., Zea-Bonilla, T., Martín-Sánchez, P. M., and Pérez-Jiménez, R. M. 2008. First report of Macrophomina phaseolina causing crown and root rot of strawberry in Spain. Plant Pathol. 57:382.

Baayen, R. P., O’Donnell, K., Bonants, P. J. M., Cigelnik, E., Kroon, L. P. N. M., Roebroeck, E. J. A., and Waalwijk, C. 2000. Gene genealogies and AFLP analyses in the Fusarium oxysporum complex identify monophyletic and nonmonophyletic formae speciales causing wilt and rot disease. Phytopathology 90:891-900.

Bahar, M., and Shahab, H. 2012. Analysis of Iranian isolates of Fusarium solani using morphological, pathogenicity and microsatellite DNA marker characterization. Afr. J. Biotechnol. 11:474-482. 
Bejarano-Alcázar, J., Blanco-López, M. A., Melero-Vara, J. M., and JiménezDíaz, R. M. 1996. Etiology, importance, and distribution of Verticillium wilt of cotton in southern Spain. Plant Dis. 80:1233-1238.

Berruezo, L. A., Cárdenas, G. E., Harries, E. M., Stenglein, S. A., Curti, R. N., Rodriguero, M. S., and Galván, M. Z. 2018. Characterization of Fusarium species associated with tobacco diseases in Northwestern Argentina. Eur. J. Plant Pathol. 151:1065-1079.

Brasileiro, T. R. V. B., Coimbra, M. R. M., Antonio de Morais, M., Jr., and Tinti de Oliveria, N. 2004. Genetic variability within Fusarium solani species as revealed by PCR-fingerprinting based on PCR markers. Braz. J. Microbiol. 35:205-210.

Burton, J. W., Miranda, L. M., Carter, T. E., Jr., and Bowman, D. T. 2012. Registration of 'NC-Miller' Soybean with High Yield and High Seed-Oil Content. J. Plant Regist. 6:294-297.

Bushelman, S. J., Callen, J. P., Roth, D. N., and Cohen, L. M. 1995. Disseminated Fusarium solani infection. J. Am. Acad. Dermatol. 32:346-351.

Ceja-Torres, L. F., Mora-Aguilera, G., Teliz, D., Mora-Aguilera, A., SánchezGarcía, P., Muñoz-Ruíz, C., Tlapal-Bolaños, B., and De La Torre-Almaraz, R. 2008. Fungi prevalence and etiology of strawberry dry wilt under different crop management systems. Agrociencia 42:451-461.

Chamorro, M., Aguado, A., and De los Santos, B. 2016. First report of root and crown rot caused by Pestalotiopsis clavispora (Neopestalotiopsis clavispora) on strawberry in Spain. Plant Dis. 100:1495.

Chandra, N. S., Wulff, E. G., Udayashankar, A. C., Nandini, B. P., Niranjana, S. R., Mortensen, C. N., and Prakash, H. S. 2011. Prospects of molecular markers in Fusarium species diversity. Appl. Microbiol. Biotechnol. 90: 1625-1639.

Chehri, K. 2016. Molecular identification of pathogenic Fusarium species, the causal agents of tomato wilt in western Iran. J. Plant Prot. Res. 56:143-148.

Costa, S. S., Moreira, G. M., and Pfenning, L. H. 2017. Development of a PCR protocol for the identification and detection of Fusarium solani f. sp. piperis from soil and roots of black pepper (Piper nigrum). Trop. Plant Pathol. 42: 55-59.

De Cal, A., Martínez-Treceño, A., López-Aranda, J. M., and Melgarejo, P. 2004. Chemical alternatives to methyl bromide in Spanish strawberry nurseries. Plant Dis. 88:210-214.

De Cal, A., Pascual, S., Larena, I., and Melgarejo, P. 1995. Biological control of Fusarium oxysporum f. sp. lycopersici. Plant Pathol. 44:909-917.

De la Lastra, E., Basallote-Ureba, M. J., De los Santos, B., Miranda, L., VelaDelgado, M. D., and Capote, N. 2018. A TaqMan real-time polymerase chain reaction assay for accurate detection and quantification of Fusarium solani in strawberry plants and soil. Sci. Hortic. (Amsterdam) 237:128-134.

de los Santos, B., Porras, M., Blanco, C., Barrau, C., and Romero, F. 2002. First report of Phytophthora cactorum on strawberry plants in Spain. Plant Dis. 86:1051

Delcán, J., Moyano, C., Raposo, R., and Melgarejo, P. 2002. Storage of Botrytis cinerea using different methods. J. Plant Pathol. 84:3-9.

Domínguez, P., Miranda, L., Medina, J. J., de los Santos, B., Talavera, M., Daugovish, O., Soria, C., Chamorro, M., and López-Aranda, J. M. 2016. Evaluation of non-fumigant alternative soil treatments for strawberry production in Huelva (Spain). Int. J. Fruit Sci. 16 (sup1):28-36.

Domínguez, P., Miranda, L., Soria, C., de los Santos, B., Chamorro, M., Romero, F., Daugovish, O., López-Aranda, J. M., and Medina, J. J. 2014. Soil biosolarization for sustainable strawberry production. Agron. Sustain. Dev. 34:821-829.

Fracchia, S., Garcia-Romera, I., Godeas, A., and Ocampo, J. A. 2000. Effect of the saprophytic fungus Fusarium oxysporum on arbuscular mycorrhizal colonization and growth of plants in greenhouse and field trials. Plant Soil 223:177-186.

Gao, X., Jackson, T. A., Lambert, K. N., Li, S., Hartman, G. L., and Niblack, T. L. 2004. Detection and quantification of Fusarium solani $\mathrm{f}$. sp. glycines in soybean roots with real-time quantitative polymerase chain reaction. Plant Dis. 88: 1372-1380.

Garrido, C., Carbú, M., Fernández-Acero, F. J., Budge, G., Vallejo, I., Colyer, A., and Cantoral, J. M. 2008. Isolation and pathogenicity of Colletotrichum spp. causing anthracnose of strawberry in south west Spain. Eur. J. Plant Pathol. $120: 409-415$.

Guijarro, B., Larena, I., Melgarejo, P., and De Cal, A. 2017. Adaptive conditions and safety of the application of Penicillium frequentans as a biocontrol agent on stone fruit. Int. J. Food Microbiol. 254:25-35.

Ke, X., Lu, M., and Wang, J. 2016. Identification of Fusarium solani species complex from infected zebrafish (Danio rerio). J. Vet. Diagn. Invest. 28: 688-692.

Laurence, M. H., Howard, C., Summerell, B. A., and Liew, E. C. Y. 2016. Identification of Fusarium solani f.sp. phalaenopsis in Australia. Australas. Plant Dis. Notes 11:15.
Leslie, J. F., Pearson, C. A. S., Nelson, P. E., and Toussoun, T. A. 1990. Fusarium species from corn, sorghum, and soybean fields in the central and eastern United States. Phytopathology 80:343-350.

Leslie, J. F., and Summerell, B. A., eds. 2006. The Fusarium Laboratory Manual, 1st ed. Backwell Publishing, Ames, IA.

Li, Y., Mao, L., Yan, D., Ma, T., Shen, J., Guo, M., Wang, Q., Ouyang, C., and Cao, A. 2014. Quantification of Fusarium oxysporum in fumigated soils by a newly developed real-time PCR assay to assess the efficacy of fumigants for Fusarium wilt disease in strawberry plants. Pest Manag. Sci. 70:1669-1675.

Lievens, B., Rep, M., and Thomma, B. P. 2008. Recent developments in the molecular discrimination of formae speciales of Fusarium oxysporum. Pest Manag. Sci. 64:781-788.

Manici, L. M., Caputo, F., and Baruzzi, G. 2005. Additional experiences to elucidate the microbial component of soil suppressiveness towards strawberry black root rot complex. Ann. Appl. Biol. 146:421-431.

Mehl, H. L., and Epstein, L. 2007. Identification of Fusarium solani f. sp. cucurbitae race 1 and race 2 with PCR and production of disease free pumpkin seeds. Plant Dis. 91:1288-1292.

Michielse, C., and Rep, M. 2009. Pathogen profile update: Fusarium oxysporum. Mol. Plant Pathol. 10:311-324.

Muraosa, Y., Schreiber, A. Z., Trabasso, P., Matsuzawa, T., Taguchi, H., Moretti, M. L., Mikamia, Y., and Kameia, K. 2014. Development of cycling probe-based real-time PCR system to detect Fusarium species and Fusarium solani species complex (FSSC). Int. J. Med. Microbiol. 304:505-511.

Nash, S. M., and Snyder, W. C. 1962. Quantitative estimations by plate counts of propagules of the bean root rot Fusarium in field soils. Phytopathology 52: 567-572.

O’Donnell, K., Humber, R. A., Geiser, D. M., Kang, S., Park, B., Robert, V. A. R. G., Johnston, P. R., Aoki, T., Rooney, A. P., and Rehner, S. A. 2012 Phylogenetic diversity of insecticolous fusaria inferred from multilocus DNA sequence data and their molecular identification via FUSARIUM-ID and Fusarium MLST. Mycologia 104:427-445.

O’Donnell, K., Kistler, H. C., Cigelnik, E., and Ploetz, R. C. 1998. Multiple evolutionary origins of the fungus causing Panama disease of banana: Concordant evidence from nuclear and mitochondrial gene genealogies. Proc. Natl. Acad. Sci. 95:2044-2049.

Oddino, C., Marinelli, A., Zuza, M., and March, G. J. 2008. Influence of crop rotation and tillage on incidence of brown root rot of peanut caused by Fusarium solani in Argentina. Can. J. Plant Pathol. 30:575-580.

Pastrana, A. M., Basallote-Ureba, M. J., and Capote, N. 2017. Symptomless reservoirs of Fusarium oxysporum f. sp. fragariae and alternative hosts of Fusarium solani pathogenic to strawberry. J. Plant Pathol. 99:141-148.

Pastrana, A. M., Capote, N., De los Santos, B., Romero, F., and Basallote-Ureba, M. J. 2014. First report of Fusarium solani causing crown and root rot on strawberry crops in Southwestern Spain. Plant Dis. 98:161.

Raposo, R., Colgan, R., Delcan, J., and Melgarejo, P. 1995. Application of an automated quantitative method to determine fungicide resistance in Botrytis cinerea. Plant Dis. 79:294-296.

Redondo, C., Villarino, M., Larenas, J., Melgarejo, P., and De Cal, A. 2012 Enfermedades emergentes en los viveros de altura de fresa tras la retirada total del bromuro de metilo en 2009. [Emerging diseases in high-altitude strawberry nurseries after the total removal of methyl bromide in 2009]. Poster session presented at: XVI Congreso Nacional de la Sociedad Española de Fitopatología, September 2012, Málaga, Spain.

Rohlf, E. J. 2002. NTSYS-pc: Numerical taxonomy and multivariate analysis system. New York: Applied Biostatistics Inc. Exeter Software Setauket. Ref Type: Computer Program.

Rojo, F. G., Reynoso, M. M., Ferez, M., Chulze, S. N., and Torres, A. M. 2007. Biological control by Trichoderma species of Fusarium solani causing peanut brown root rot under field conditions. Crop Prot. 26:549-555.

Rupe, J. C., Robbins, R. T., and Gbur, E. E., Jr. 1997. Effect of crop rotation on soil population densities of Fusarium solani and Heterodera glycines and on the development of sudden death syndrome of soybean. Crop Prot. 16: 575-580.

Snedecor, G. W., and Cochran, W. G. 1980. Statistical Methods, 7th ed. Iowa State University, Ames, IA

Teruhiko, S., Masahiro, N., and Keiichi, H. 2001. Control of Fusarium wilt of strawberry by soil solarization using mulching and tunnel-covering combining with irrigation of solar-heated water. Bull. Nara Prefectural Agric. Exp. Stn. 32:1-7.

Trabelsi, R., Sellami, H., Yâakoub, G., Krid, S., Cheffi, M., Kammoun, S., Dammak, M., Mseddi, A., Gdoura, R., and Triki, M. A. 2017. Morphological and molecular characterization of Fusarium spp. associated with olive trees dieback in Tunisia. 3 Biotech. 7:28.

Villarino, M., Melgarejo, P., and De Cal, A. 2016. Growth and aggressiveness factors affecting Monilinia spp. survival peaches. Int. J. Food Microbiol. 224: $22-27$. 